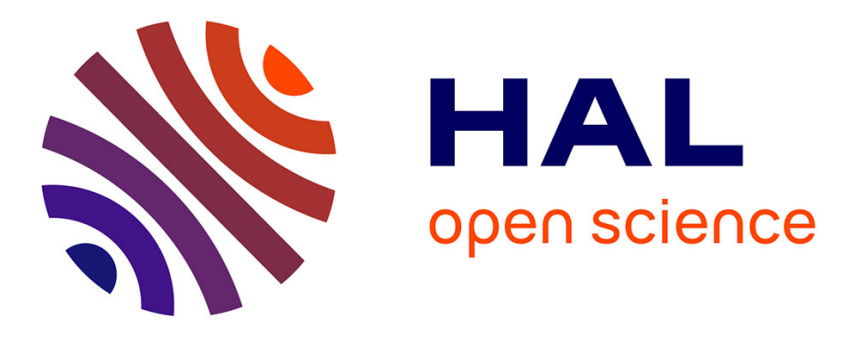

\title{
Energy-efficient Localization for Virtual Fencing
}

\author{
Raja Jurdak, Peter Corke, Dhinesh Dharman, Guillaume Salagnac, Chris
}

Crossman, Philip Valencia, Greg Bishop-Hurley

\section{To cite this version:}

Raja Jurdak, Peter Corke, Dhinesh Dharman, Guillaume Salagnac, Chris Crossman, et al.. Energyefficient Localization for Virtual Fencing. The 9th International Conference on Information Processing in Sensor Networks, IPSN 2010, Apr 2010, Stockholm, Sweden. pp.388-389. inria-00486684

\section{HAL Id: inria-00486684 \\ https://hal.inria.fr/inria-00486684}

Submitted on 26 May 2010

HAL is a multi-disciplinary open access archive for the deposit and dissemination of scientific research documents, whether they are published or not. The documents may come from teaching and research institutions in France or abroad, or from public or private research centers.
L'archive ouverte pluridisciplinaire HAL, est destinée au dépôt et à la diffusion de documents scientifiques de niveau recherche, publiés ou non, émanant des établissements d'enseignement et de recherche français ou étrangers, des laboratoires publics ou privés. 


\title{
Energy-efficient Localization for Virtual Fencing
}

\author{
Raja Jurdak, Peter Corke*, Dhinesh Dharman, Guillaume Salagnac ${ }^{+}$, \\ Chris Crossman, Philip Valencia, Greg-Bishop Hurley \\ Autonomous Systems Laboratory, CSIRO ICT Centre, Brisbane,QLD Australia \\ ${ }^{*}$ Queensland University of Technology Brisbane QLD Australia \\ + INSA Lyon France
}

\section{OVERVIEW}

This poster addresses the tradeoff between energy consumption and localization performance in a mobile sensor network application. It focuses on combining GPS location with more energy-efficient location sensors to bound position estimate uncertainty in order to prolong node lifetime. The focus is on an outdoor location monitoring application for tracking cattle using smart collars that contain wireless sensor nodes and GPS modules [1]. We use empirically-derived models to explore duty cycling strategies for maintaining position uncertainty within specified bounds. Specifically we explore the benefits of using short-range radio contact logging alongside GPS as an energy-inexpensive means of lowering uncertainty while the GPS is off. Results show that GPS combined with radio-contact logging is effective in extending node lifetime while meeting applicationspecific positioning criteria.

\section{ENERGY-EFFICIENT LOCALIZATION}

The cattle monitoring collars incorporate a Fleck node, a GPS module, and an audio board for generating audio cues to indicate to animals that they are crossing a virtual fence line. The Fleck node itself comprises an Atmel-1281 MCU and NRF905 radio. Four D-Cell batteries in series provide power to all the collar components via several switch-mode regulators.

The active mode power consumption of the GPS board is by far the largest of all components at $165 \mathrm{~mW}$, compared to $50 \mathrm{~mW}$ for the radio and $18 \mathrm{~mW}$ for the MCU. Figure 2 compares the collar node energy consumption for an always on GPS module (Figure 1(a)) against a

Permission to make digital or hard copies of all or part of this work for personal or classroom use is granted without fee provided that copies are not made or distributed for profit or commercial advantage and that copies bear this notice and the full citation on the first page. To copy otherwise, to republish, to post on servers or to redistribute to lists, requires prior specific permission and/or a fee.

Copyright 200X ACM X-XXXXX-XX-X/XX/XX ...\$5.00.

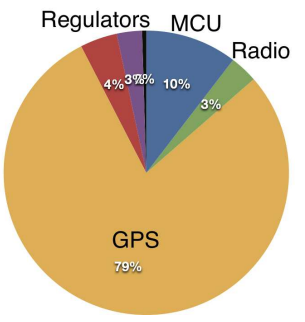

(a) Always on GPS

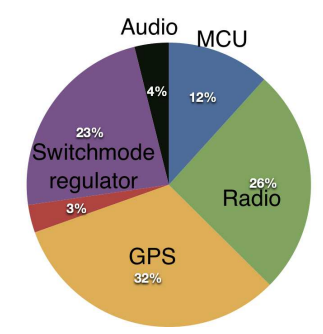

(b) GPS with duty cycle of $5 \%$

\section{Figure 1: Impact of GPS duty cycling}

$5 \%$ duty cycled GPS module. Both configurations use a $10 \%$ radio duty cycle (using low-power listening). The always-on GPS module accounts for $88 \%$ of the power consumption of $209 \mathrm{~mW}$ and limits the nodes' lifetime to 19 days, while $5 \%$ duty cycle GPS accounts for about a third of the overall node power consumption of $25 \mathrm{~mW}$, which extends the nodes' lifetime by a factor of 7.5. This confirms the importance of duty cycling the GPS on the mobile nodes. In both scenarios, the MCU remains on only as required to service the GPS or radio, which couples its duty cycle to these components' duty cycles.

\subsection{GPS Duty Cycling}

While GPS provides the most reliable absolute location estimate outdoors, its high power consumption demands duty cycling in order to achieve the target lifetime.

Whenever the GPS is powered off at time $t_{k}$, and until it next acquires lock, the position uncertainty grows progressively according to

$$
U(t)=\bar{s}\left(t-t_{k}\right)+U_{0}, t \geq t_{k}
$$

where $\bar{s}$ is the assumed speed and $U_{0}$ is the initial uncertainty. We require $U$ to remain with an absolute acceptable uncertainty (AAU), $U<$ AAU. Because the GPS has a finite lock time, $t_{L}$, we need to start the lock process after at most $T_{\max }$ seconds, where

$$
T_{\max }=\frac{A A U-U_{0}}{\bar{s}}-t_{L}
$$


is the GPS off time. The lock time, $t_{L}$, has a weak dependence on the length of time that the GPS has been off and on the deployment environment. The assumed speed is a critical parameter that controls the uncertainty/energy tradeoff. Offline analysis of a dataset that contains GPS data from 35 collar nodes collected continuously (once per second) over 2 days indicates an average speed of only $0.4 \mathrm{~m} / \mathrm{sec}$, and $95 \%$ of the time the cows move at $1 \mathrm{~m} / \mathrm{sec}$ or less, with an absolute maximum of $3.5 \mathrm{~m} / \mathrm{sec}$. Speed can also be set dynamically according to the latest observed speed for each node.

\subsection{Coupling GPS and contact logging}

Mobile nodes can use non-GPS relative localization signals to reduce position uncertainty while the GPS module is powered off [2]. In our application, we exploit the fact that the mobile nodes (cows) tend to cluster together making short range $\mathrm{RF}$ contact logging feasible. Consider that node A has powered off its GPS and is growing its estimated uncertainty as a function of time. Receiving a beacon from node $\mathrm{B}$ implies that node $\mathrm{A}$ is within the contact radius $R$.

However the beacon could also include node B's last measured position $x_{k}^{B}$ and its current uncertainty estimate $U^{B}$. If $U^{B}+R<U^{A}$ then node $\mathrm{B}$ is nearby and has a lower uncertainty than node $A$. In this case node A lowers its uncertainty estimate to $U^{A}:=U^{B}+R$

Lowering the estimated uncertainty enables node A to keep its GPS off for longer, which reduces its energy consumption. If a node's estimated uncertainty approaches AAU, it turns its GPS on.

If all nodes run this algorithm, the expensive GPS position fix is shared across the nodes. The fairness of the algorithm stems from the fact that when node $\mathrm{A}$ relies on node $\mathrm{B}$ for its position estimate, $U^{A}>U^{B}$, and if the two nodes use the same assumed speed to grow their uncertainty, then node A will decide to turn on its GPS before node B, which allows B to rely on $\mathrm{A}$ for its position estimate in the next cycle.

\subsection{Results}

To evaluate the impact of our algorithms, we have implemented the duty cycling strategy in a Python-based simulator using the large dataset of actual cow position. Figure 2 illustrates the impact of contact logging on GPS duty cycling for two nodes with dynamically set speeds. Without contact logging, Figure 2(a), each node independently tracks its uncertainty estimate and acquires a GPS position fix whenever its uncertainty approaches AAU of $50 \mathrm{~m}$, resulting in 5 fixes for node 1 and 4 fixes for node 2 . Using contact logging, the nodes can reduce their GPS fixes to 3 and 2 respectively in the same time window. Figure 3 summarizes the impact of contact radius on GPS duty cycle and er-

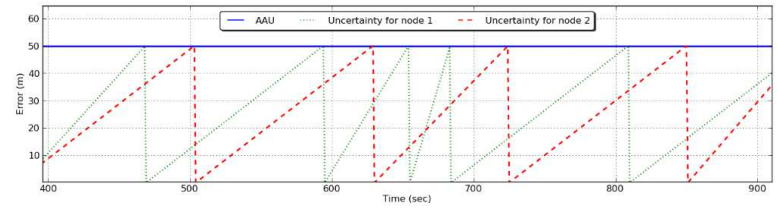

(a) Error behaviour for GPS duty cycling

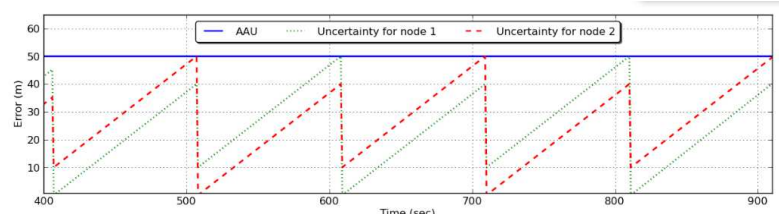

(b) Error behaviour for GPS duty cycling coupled with contact logging

\section{Figure 2: Impact of contact logging on GPS duty cycles}

ror rate over the entire dataset. The optimal contact radius is at $10 \mathrm{~m}$, with a $25-33 \%$ reduction in duty cycle over GPS duty cycling $(\mathrm{R}=0)$. Extending the contact radius further appears to have a detrimental effect on duty cycle. Contact logging improves the error rate in all cases, particularly the dynamic speed model.
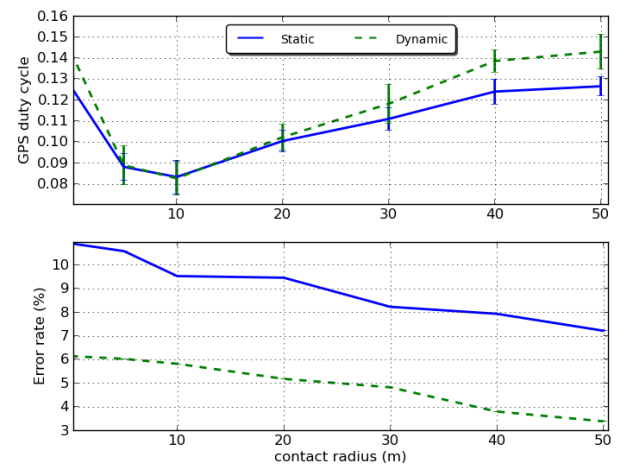

Figure 3: Effect of contact radius

\section{CONCLUSION}

Coupling GPS duty cycling with short-range radio contact logging can both extend the lifetime and reduce positioning errors in a multi-agent tracking application.

\section{REFERENCES}

[1] T. Wark et al. The design and evaluation of a mobile sensor/actuator network for autonomous animal control. In IPSN '0\%, 2007.

[2] L. Chan et al. Collaborative localization: Enhancing wifi-based position estimation with neighborhood links in clusters. In Pervasive, 2006. 